\title{
Changes in atmospheric shortwave absorption as important driver of dimming and brightening
}

Article

Accepted Version

Schwarz, M., Folini, D., Yang, S., Allan, R. P. and Wild, M. (2020) Changes in atmospheric shortwave absorption as important driver of dimming and brightening. Nature Geoscience, 13 (2). pp. 110-115. ISSN 1752-0894 doi: https://doi.org/10.1038/s41561-019-0528-y Available at https://centaur.reading.ac.uk/88996/

It is advisable to refer to the publisher's version if you intend to cite from the work. See Guidance on citing.

To link to this article DOI: http://dx.doi.org/10.1038/s41561-019-0528-y

Publisher: Springer Nature

All outputs in CentAUR are protected by Intellectual Property Rights law, including copyright law. Copyright and IPR is retained by the creators or other copyright holders. Terms and conditions for use of this material are defined in the End User Agreement.

www.reading.ac.uk/centaur 
Central Archive at the University of Reading

Reading's research outputs online 


\section{Changes in atmospheric shortwave}

\section{absorption as important driver of}

\section{dimming and brightening}

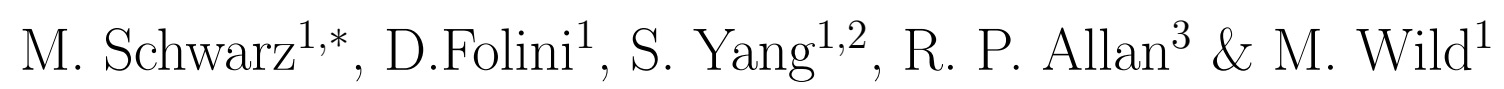

December 8, 2019

1. Institute for Atmospheric and Climate Science, ETH Zurich, CH-8092 Zurich, Switzerland.

2. National Meteorological Information Center, China Meteorological Administration, Beijing, China

3. Department of Meteorology, National Centre for Earth Observation, Whiteknights, University of Reading, Earley Gate, PO Box 243, Reading RG6 6BB, UK

The amount of solar (shortwave) radiation reaching the Earth's surface underwent substantial variations over recent decades. Since the 1950s, surface shortwave radiation gradually decreased at widespread locations. In Europe, this so-called surface dimming continued until the late 1980s when surface brightening set in and surface shortwave radiation increased again. In China, the dimming leveled off in the 1980s but did not turn into brightening until 2005. Changes in clouds and aerosol are the prime potential causes for 
the phenomenon but the scientific community has not yet reached consensus about the relative role of the different potential forcing agents. Here we bring together colocated long-term observational data from surface and space to study decadal changes of the shortwave energy balance in Europe and China from 1985-2015. Within this observation-based framework, we show that increasing net shortwave radiation at the Top-of-the-Atmosphere and decreasing atmospheric shortwave absorption each contribute roughly half to the observed brightening trends in Europe. For China, we find that the continued dimming until 2005 and the subsequent brightening occurred despite opposing trends in the Top-of-the-Atmosphere net shortwave radiation. This shows that changes in atmospheric shortwave absorption are a major driver of European brightening and the dominant cause for the Chinese surface trends. Although the observed variations can not be attributed unambiguously, we discuss potential causes for the observed changes.

It is well documented that the amount of shortwave radiation reaching the Earth's surface $\left(I_{s f c}^{\downarrow}\right)$ underwent substantial decadal variations since measurements became available in the first half of the $20^{\text {th }}$ century [1]. Since the 1950s, $I_{s f c}^{\downarrow}$ gradually decreased until the late 1980s at widespread locations [2]. In Europe and other parts of the world, this "dimming" phase was followed by a "brightening" period in which $I_{s f c}^{\downarrow}$ started to increase again [3]. In China, the dimming leveled off in the 1980s but did not turn into brightening until $2005[4]$.

Here we look at this phenomenon from a shortwave energy balance perspective. The part of the incoming shortwave radiation at the Top-of-the-Atmosphere (TOA) which is not reflected back to space is absorbed within the climate system $\left(I_{\text {toa }}^{\text {net }}=I_{\text {toa }}^{\downarrow}-I_{\text {toa }}^{\uparrow}\right)$. This net incoming shortwave radiation at TOA itself is either absorbed in the atmosphere $\left(A_{a t m}\right)$ or absorbed at the surface $\left(A_{s f c}\right): I_{t o a}^{n e t}=A_{a t m}+A_{s f c}$. The surface absorption $\left(A_{s f c}\right)$ is determined by $I_{s f c}^{\downarrow}$ and the surface albedo $(\alpha)$ via: $A_{s f c}=I_{s f c}^{\downarrow} \cdot(1-\alpha)[5,6]$. Due to the principle of energy conservation, changes in the shortwave energy balance must be counterbalanced at all times. Thus, the changes in $I_{s f c}^{\downarrow}$ during dimming and 
brightening imply that other components of the shortwave energy balance must have changed accordingly.

Evidence was reported that the dimming and brightening affected the climate system by weakening and strengthening the surface temperature increase from greenhouse warming $[7,8]$, by changing the global hydrological cycle [9] and local precipitation systems like the Asian monsoon [10], as well as by altering the global carbon cycle [11]. It was also recognized that the impacts of dimming and brightening on the climate system might be substantially different or even opposite, depending on which components of the shortwave energy balance determine the surface changes $[12,8,13]$.

The fact that surface temperatures effectively respond to changes in $I_{\text {toa }}^{\text {net }}$ is well known and even considered in developing geoengineering techniques (i.e., solar radiation modification) to reduce the impact from global greenhouse warming [14]. The surface temperature response to changes in $A_{a t m}$ is more versatile. It not only depends on the change in the surface energy balance but also on the change in atmospheric temperature, atmospheric stability, and the coupling between surface and higher layers $[15,16,17,8,18]$.

The global precipitation response to dimming and brightening might also be different depending on whether it is governed by $I_{\text {toa }}^{\text {net }}$ or $A_{\text {atm }}$. Evaporation - which, in a global perspective equals precipitation - is determined by the surface radiation balance and is, therefore, sensitive to changes in the downward solar radiation [9]. Since evaporation also depends on surface temperatures and since surface temperature responds differently to changes changes in $I_{\text {toa }}^{\text {net }}$ and $A_{a t m}$, the total precipitation response to dimming and brightening might even have an opposite sign when $A_{\text {atm }}$ instead of $I_{\text {toa }}^{\text {net }}$ forces the surface changes [19]. This also applies for changes in regional precipitation systems like the East Asian summer monsoon [13].

To better understand the causes and impacts of declining surface solar radiation (dimming) and subsequent recovery (brightening) we compiled the best available observational data sets from surface and space to be able to contrast top-of-the-atmosphere, in atmosphere, and surface energy fluxes 
${ }_{76}$ Flux changes inferred from colocated observations.

We use $I_{s f c}^{\downarrow}$ data from the Baseline Surface Radiation Network (BSRN [20]), the Global Energy Balance Archive (GEBA [21]), and the China Meterological Administration (CMA [4]) and combine them with colocated surface albedo estimates from the Global Land Surface Satellites (GLASS [22]), and colocated $I_{\text {toa }}^{\text {net }}$ estimates from the DEEP-C reconstruction $[23,24]$. The combination of point and gridded data is justified as we only select stations which are representative of their larger surroundings according to objective criteria [25]. For the period where all data is available (i.e., 1985 to 2015), we compute regionally averaged annual mean anomaly time series of all components of the shortwave energy balance based on colocated homogeneous records [26] of 71 stations in Europe and 61 stations in China. The methods section provides descriptions of the data sets, the data processing, as well as details on the uncertainty propagation strategy.

Figure 1 displays the station distribution in Europe and in China and shows the estimated long term (2000-2015) annual mean $A_{a t m}$ for all stations expresses as a fraction of $I_{\text {toa }}^{\downarrow}$. Globally averaged, roughly $23 \pm 2 \%$ of $I_{\text {toa }}^{\downarrow}$ is absorbed in the atmosphere [27, $28,6,29]$. For Europe, the long term mean $A_{a t m}$ is close to the global value of $23 \%$ (see Figure 1a) [30]. For China, however, we find that $A_{\text {atm }}$ even exceeds $31 \%$ of $I_{\text {toa }}^{\downarrow}$ at some sites in highly developed regions in the southern and eastern parts of China.

Figure 2 shows the regionally averaged annual anomaly time series for $I_{s f c}^{\downarrow}, \alpha, A_{s f c}$, $A_{a t m}$, and $I_{\text {toa }}^{\text {net }}$ as well as associated uncertainties, which we obtained by propagating the measurement uncertainties using a bootstrapping approach (see methods section for details). For the period where data of all components of the shortwave energy balance are available (i.e., 1985-2015) we compute linear trends as well as their uncertainties and significance for different sub-periods as shown in Figure 3 and in the respective tables in the supplemental material.

For Europe, the well-documented decrease in $I_{s f c}^{\downarrow}$ until roughly 1980 [3] and the following gradual increase of $I_{s f c}^{\downarrow}[1,31]$ is clearly visible in the lowest panel of Figure 2c. The surface albedo only shows little variability and no trends. Consequently, the surface absorbed flux $\left(A_{s f c}\right)$ is closely following the variability of $I_{s f c}^{\downarrow}$. Over the whole 31-year 
period $A_{s f c}$ increases by $+1.7 \pm 0.1 \mathrm{~W} \mathrm{~m}^{-2}$ decade ${ }^{-1}$ with high statistical significance.

In Europe, $I_{\text {toa }}^{\text {net }}$ tends to gradually increase throughout the whole period. However, the observed trends in $I_{\text {toa }}^{\text {net }}$ are considerably smaller and less significant than those observed at the surface (see Fig. 3a \& 3c), uncovering trends in $A_{\text {atm }}$ which are comparable but of opposite sign to those at the TOA. For the whole 31-year period we find trends in $I_{t o a}^{\text {net }}$ and $A_{a t m}$ of $+1.0 \pm 0.1 \mathrm{~W} \mathrm{~m}^{-2}$ decade $^{-1}$ and $-0.7 \pm 0.1 \mathrm{~W} \mathrm{~m}^{-2}$ decade ${ }^{-1}$, respectively. The positive trend in the surface absorption during the European brightening period is thus determined roughly equally from more incoming radiation at TOA and less radiation absorbed within the atmosphere.

For some sub-periods, the trend in $A_{a t m}$ even outweighs the one of $I_{\text {toa }}^{\text {net }}$. The largest trend in $A_{a t m}$ in Europe appears in the 15-year period centered around mid 1998. It shows a decrease in $A_{a t m}$ of $-2.1 \pm 0.4 \mathrm{~W} \mathrm{~m}^{-2}$ decade ${ }^{-1}$ while in that period $A_{s f c}$ and $I_{\text {toa }}^{\text {net }}$ show trends of $+3.6 \pm 0.3 \mathrm{~W} \mathrm{~m}^{-2}$ decade $^{-1}$ and $+1.6 \pm 0.2 \mathrm{~W} \mathrm{~m}^{-2}$ decade $^{-1}$.

In China, $I_{s f c}^{\downarrow}$ shows a strong decrease prior to 1980 (see Fig. 2f). This "dimming" leveled off in China during the 1980s and 1990s and $I_{s f c}^{\downarrow}$ only started to recover to some degree during the end of the observational period $[32,4]$. This trend reversal is likely related to the implementation of more rigorous air quality measures in China after 2000, and thus to a reduction in air pollution $[33,34,35,36]$. Also in China, the surface albedo shows relatively little variability and no trend such that $A_{s f_{c}}$ again closely follows the temporal evolution of $I_{s f c}^{\downarrow}$. For the whole 31-year period, the fluxes in China do not show any significant trends. However, for shorter sub-periods large and significant trends are apparent.

The trends in $A_{s f c}$ in the first part of the total record are typically around $-1.0 \pm$ $0.2 \mathrm{~W} \mathrm{~m}^{-2}$ decade $^{-1}$ with limited statistical significance. At the same time, more radiation enters the climate system at the TOA. The negative trend at the surface and the positive trend at the TOA can only occur at the same time when large positive trends in $A_{a t m}$ are prevalent. These positive trends in $A_{\text {atm }}$ range up to $+3.7 \pm 0.4 \mathrm{~W} \mathrm{~m}^{-2}$ decade $e^{-1}$ for some periods. For the 23-year period from 1985 to 2009 (centered mid 1996), in which dimming in China occurs, a significant positive trend in $A_{\text {atm }}$ of $+1.5 \pm$ 
$0.2 \mathrm{~W} / \mathrm{m}^{2}$ decade ${ }^{-1}$ coincides with trends in $A_{s f c}$ and $I_{\text {toa }}^{\text {net }}$ of $-0.7 \pm 0.2 \mathrm{~W} \mathrm{~m}^{-2}$ decade and $+0.8 \pm 0.2 W^{-2}$ decade ${ }^{-1}$, respectively.

For the period from 2001 to 2015 (centered in mid 2008), when pronounced brightening is evident in China, trends of $-1.8 \pm 0.3 \mathrm{Wm}^{-2}$ decade $^{-1},-3.2 \pm 0.4 \mathrm{~W} \mathrm{~m}^{-2}$ decade $e^{-1}$, and $+1.4 \pm 0.2 \mathrm{~W} \mathrm{~m}^{-2}$ decade ${ }^{-1}$ are observed for $I_{t o a}^{\text {net }}, A_{\text {atm }}$, and $A_{s f c}$, respectively.

We can summarize the results as follows: In Europe, the increase in the amount of net incoming radiation at the TOA and the decrease in atmospheric absorption each contributed roughly half to the increase in surface absorption and therefore to the European brightening. In China, a transition from dimming to brightening is found around the year 2005. Before that, increasing atmospheric absorption led to dimming at the surface (and corresponding decrease in surface absorption) despite increasing TOA net radiation. After 2005, all trends reversed in China and decreasing atmospheric absorption led to surface brightening (and corresponding increase in surface absorption) despite decreasing TOA net radiation. This is to date the most direct observational evidence that changes in atmospheric absorption are central to the brightening and dimming phenomenon.

\section{Potential causes of the phenomenon.}

Because of the profound consequences of dimming and brightening for the climate system, it is important to identify the governing processes behind the phenomenon. A substantial body of literature exists, which investigated potential causes of the changes in surface solar radiation. Scientific consensus about the relative role of different forcing agents as well as the role of internal variability has, however, not yet been reached $[37,1,38]$. This is also because most previous observational analyses studied dimming and brightening from a surface perspective only, as long-term high-quality satellite observations of TOA fluxes and surface albedo were not yet available.

Our approach goes beyond this often used surface-only perspective and allows a simultaneous observation-based quantification of changes in the partitioning of $I_{t o a}^{\text {net }}, A_{s f c}$, 
and $A_{a t m}$ during brightening and dimming, which in turn facilitates a more detailed insight into the governing processes and their impacts on climate. However, a challenge in all observation-based approaches is that various different forcing agents act simultaneously. It is thus difficult to attribute changes to individual forcing agents. Nevertheless, our results offer additional constraints to judge which of the primary forcing agents notably clouds, surface albedo, water vapor, and scattering and absorbing aerosols may be able to explain the observed changes in shortwave fluxes (note that changes the radiatively active gaseous compounds $\mathrm{O}_{3}, \mathrm{~N}_{2} \mathrm{O}, \mathrm{CH}_{4}$, and $\mathrm{CO}_{2}$ only induce very small changes [39]).

Our main finding - namely that changes in atmospheric shortwave absorption are a major driver for the changes in the shortwave energy balance - is especially evident in China. There, a decrease in total cloud cover until 2005 was reported [40], while at the same time emissions of scattering aerosols sharply increased [41]. After 2005, an increase in clouds [42] and a decrease in emission of scattering aerosols were reported [41] . Aerosol emissions possibly also forced some of the observed cloud changes through aerosol cloud interactions [43]. In general, more radiation is reflected back to space when more clouds and scattering aerosols are present leading to a smaller $I_{\text {toa }}^{\text {net }}$ flux. The initial increase and subsequent decrease in $I_{\text {toa }}^{\text {net }}$ in our results then suggests that the changes in cloud cover must have counterbalanced and outweighed the changes in scattering aerosols. From changes in clouds and scattering aerosols alone one would expect that the TOA and surface changes are of the same sign and magnitude, but the observations actually show the opposite. Also, the radiative effect of clouds and scattering aerosols is much larger at the TOA than on $A_{a t m}[12,29,44]$. Thus, it is unlikely that changes in clouds and scattering aerosols alone lead to observed changes in the shortwave fluxes in China.

Observed changes in total water vapor path (WP) of $-0.118 \mathrm{~mm} /$ year in China from 2000 to 2015 [45] fit the observed change in $A_{a t m}$ qualitatively. However, using an empirical relation which links water vapor abundance (WP) to $A_{\text {atm }}$ (in a pristine atmosphere) [29] via $A_{a t m}=\alpha(2.1+0.86 W P)+[15.7+3.3 \ln (W P)]$ with climatological 
$W P=2.25 \mathrm{~cm}[45]$ and albedo $\alpha=0.1$ implies a change in $A_{a t m}$ due to changes in WP of only $0.3 \mathrm{~W} \mathrm{~m}^{-2}$ from 2000 to 2015 , which is much less than what is actually observed (see also reference [46]).

Considering that $\alpha$ did not change drastically in the observational period (see Figure 2) this altogether points to absorbing aerosols - of which the most prominent species is black carbon - as the prime forcing agent for the observed change in the shortwave fluxes in China. Reconsidering changes in aerosol optical depth from observations [47], reanalysis [48], and emission inventories [41] show consistent temporal changes in (absorbing) aerosols, but efforts to estimate the aerosol forcing from such data are subject to substantial uncertainties [49]. The observed changes in $A_{a t m}$ might also have contributed to the observed cloud changes via the semi-direct aerosol effect from absorbing aerosols $[50,1,51]$. Our observational results also fit modeling efforts which utilize radiative transfer models in combination with observations of aerosol optical properties which suggest that increasing atmospheric absorption due to increasing absorbing aerosols prevail $[52,16,53]$.

It is plausible that absorbing aerosols are also the main cause for the Chinese dimming in the pre-satellite era and that the high $A_{a t m}$ (Fig. 1b) is a remnant of this strong dimming. However, since direct continuous observations are not available, this can not be demonstrated conclusively.

In China, observational evidence for changes in ambient surface temperatures, clouds, wind speed, fog, precipitation, and changes of the Asian summer monsoon was reported (see ref [43] and references therein). It is plausible that these changes are to some degree caused by the changing $A_{a t m}$ as main radiative response to changing absorbing aerosols.

Mitigation of aerosol pollution in China and associated surface brightening then may not necessarily be associated with large additional temperature forcing as suggested by modeling studies [54]. Our study demonstrates that the SW TOA forcing, thus the shortwave energy input into the climate system, has been positive in the dimming period from 1985 to 2005 but negative thereafter.

In Europe, $A_{a t m}$ and $I_{\text {toa }}^{\text {net }}$ each contributed roughly half to the surface brightening. 
Several studies highlighted that changes in clouds play a vital role for dimming and brightening in Europe $[55,56,57]$. At the same time, other studies $[58,59]$ suggest declining aerosols emissions in Europe [60] as main forcing for the European surface trends. Although these decreasing emissions could also have led to declining aerosolcloud interactions, evidence was reported that these aerosol indirect effects contribute little to the European brightening $[61,62,55]$. We demonstrate for the first time that also in Europe changing $A_{a t m}$ significantly contributes to the surface changes. This would fit to decreasing black carbon emissions in Europe obtained from emission inventories [60]. Our findings, therefore, point to a combination of clouds and aerosols as main forcing agents in Europe, as also suggested previously [63, 55].

This study demonstrates that using combined colocated surface and TOA observations allows valuable insight into the physical processes which govern the changes in the energy balance. The observation based, quantitative estimates of decadal scale changes of the shortwave energy balance components presented may also provide useful for the further analysis and improvement of shortcomings of global climate models [64, 65].

A specific conclusion from our results, if combined with published estimates of changes in different atmospheric constituents, is that dimming and brightening may not be attributable to a single forcing agent but that it is a result of a complex interplay between changes of different forcing agents where the role of absorbing aerosols has previously been underestimated. 


\section{Methods}

\section{Surface shortwave radiation.}

For $I_{s f c}^{\downarrow}$ we utilize data from the Baseline Surface Radiation Network (BSRN [20]), the Global Energy Balance Archive (GEBA [21]), and data from the China Meteorological Administation (CMA) [4].

The GEBA and CMA data is available as monthly mean time series. For BSRN stations, monthly mean times series from the raw two- and one-minute data are calculated according to the recommended procedure of ref. [66].

Only stations which are representative for a larger surrounding are included in the analysis, to match with the scale of the TOA data. We consider three aspects of representativeness $[67,25]$ : (1) the spatial distance up to which the temporal variability of a $I_{s f c}^{\downarrow}$ time series measured at a site can be considered representative (expressed in terms of decorrelation length, $\delta$ ), (2) spatial sampling biases $(\beta)$, and (3) spatial sampling errors $(\epsilon)$ which arise due to imperfect representativeness of the stations. In the terminology of Schwarz et al. (2018) [25], stations which do not adequately represent the temporal variations of $I_{s c f}^{\downarrow}$ (i.e. $\delta<2^{\circ}$ ) or have large (monthly) spatial sampling errors with respect to the DEEP-C grid $\left(\epsilon>16 \mathrm{~W} / \mathrm{m}^{2}, 95 \%\right.$ confidence level $)$ are excluded from the analysis. Spatial sampling biases are corrected for each station.

For the BSRN data, uncertainties of $\pm 8 \mathrm{Wm}^{-2}$ and $\pm 5 \mathrm{Wm}^{-2}$ (95\% level) for monthly and annual means were reported, respectively [68]. For the GEBA data, uncertainties for monthly and annual means of $\pm 5 \%$ and $\pm 2 \%$ (root mean square error) were reported [69]. The error of the CMA data likely does not exceed $\pm 5 \%$ and $\pm 3 \%$ for monthly and annual data [70].

The long-term stability of the $I_{s f c}^{\downarrow}$ observations is achieved by a regular calibration of the sensors against a reference with known stability, which is traceable to a known reference. BSRN measurements are calibrated annualy and tracable to the world radiometric reference (WRR) from the World Radiation Center at the Physikalisch-Meteorologisches Observatorium in Davos, Switzerland (PMOD/WRC) [71]. The CMA data is calibrated 
using a multistep approach which is traceable to a national referencef, which itself is calibated to the WRR every five years [72].

Within 38 years the WRR had a suggested total drift of less than $0.02 \%$ [68]. A quantitative assessment of how that translates into the stability of long term $I_{s f c}^{\downarrow}$ measurements is lacking. However, for well calibrated instruments, we expect sufficient stability which does not substantially influence the observed trends.

To avoid step-changes in the surface data which might occur due to changes in the instrumentation and/or relocation of the station, we assess the homogeneity of the monthly $I_{s f c}^{\downarrow}$ time series. The GEBA time series are tested regarding their homogeneity using four different homogeneity tests as described in ref. [26]. The CMA data has been analyzed and homogenized using sunshine duration data as described in ref. [4]. BSRN data is expected to be homogeneous because of the rigorous measurement standards of the BSRN [71].

After excluding stations with insufficient spatial representativeness, stations with lacking homogeneity, or stations with less than 15 years of data for all shortwave energy balance components, we use in total six BSRN and 65 GEBA stations for Europe and one BSRN and 61 CMA stations for China.

\section{TOA shortwave radiation.}

For the TOA net irradiance, we use the DEEP-C version 3 reconstruction, which is available with a spatial resolution of $0.7^{\circ}$ and monthly temporal resolution $[23,24]$. The reconstruction merges satellite SW TOA irradiances from the Clouds and Earth's Radiant Energy System (CERES) Energy Balanced and Filled Ed2.8 data set (available since 02/2000; [73, 74]) and the Wide Field of View (WFOV) Ed.3 Rev1 data set from the nonscanning instrument onboard of the Earth Radiation Budget Experiment (ERBE; available 1985-1999; [75, 76]) satellites. For the reconstruction, the ERA-Interim atmospheric reanalysis [77] and a 25km resolution global atmospheric model (HadGEM3A-GA3) with five ensemble simulations from the UPSCALE project [78] were used to homogenize the satellite data sets $[23,24]$. For the period after March 2000, CERES 
data is used. Before that, the reconstruction is based on an annual cycle calculated from the first five complete years of the CERES data (2001-2005) to which ERA-I deseasonalized radiative flux anomalies are added. The data is then adjusted such that the hemispheric $\left(60^{\circ} S-0^{\circ}\right.$ and $\left.0^{\circ}-60^{\circ} \mathrm{N}\right)$ mean deseasonalized anomalies match the corresponding hemispheric ERBE time series. With this approach, the DEEP-C data "combines the quality of the CERES data, stability of the ERBE data, and the realistic circulation changes depicted by ERA-I" [23].

We provide a comparison between the DEEP-C reconstruction and the directly measured data in Figure 4 for the areas under investigation in this study. There, all regional averages of the raw data for Europe and China from CERES EBAF v.4 (03/2000 to present; [79]), the ERBE Scanner data (1985-1989) [75], and the ERBE WFOV Nonscanner data Ed. 3 Rev.1 [76] and ERBE WFOV Nonscanner data Ed. 4 [80] (both WFOV Nonscanner data available from 1985 to 1999) are shown.

The figure shows, that the DEEP-C data follows the same temporal evolution as the directly measured data and that no spurious inhomogeneities or trends are visible in the data record.

The uncertainty of regional $I_{\text {toa }}^{\text {net }}$ from the DEEP-C reconstruction was estimated to be $\pm 5.7 \mathrm{~W} \mathrm{~m}^{-2}$ for monthly and $\pm 2.1 \mathrm{~W} \mathrm{~m}^{-2}$ for annual means (one standard-deviation confidence level) [24]. The stability of the the CERES instrument is on the order of $\pm 0.2 \mathrm{~W} \mathrm{~m}^{-2}$ decade $^{-1}[24]$ while the stability of the ERBE WFOV Nonscanner instrument is on the order of $\pm 0.35 \mathrm{~W} \mathrm{~m}^{-2}$ during the period 1985-1999 [76].

\section{Albedo.}

We use the Global Land Surface Satellite (GLASS) white sky albedo as the main albedo dataset. It is based on advanced very high resolution radiometer (GLASS-AVHRR; 1982 - 2015) and Moderate-resolution Imaging Spectrometer (GLASS-MODIS; 20002015) observations [22]. The dataset provides a high-quality gap-free, long-term, selfconsistent albedo record since 1982 with similar quality as the Moderate Resolution Imaging Spectroradiometer (MODIS) albedo data [81, 22]. The data is available in 
8-day temporal resolution with $0.05^{\circ}$. We aggregate the observations temporally to monthly means and spatially to the DEEP-C $0.7^{\circ}$ grid.

For the period after 2000, we also use the MODIS white sky surface albedo from [82]. The MODIS data currently provides one of the most reliable albedo estimates and is, therefore, used as reference data. The MODIS albedo accuracy has been proven to be well within $\pm 5 \%$ [83].

\section{Data processing.}

To calculate the surface absorbed flux, we multiply the monthly $I_{s f c}^{\downarrow}$ with monthly mean $\alpha$ estimates from GLASS-AVHRR. A step inhomogeneity in the GLASS-AVHRR data around the year 2000 was corrected by subtracting the differences between the GLASSAVHRR long-term mean before and after the year 2000. Since the MODIS albedo is currently the most reliable albedo estimate, we bias correct the GLASS-AVHRR data by subtracting the differences between the MODIS and GLASS-AVHRR data.

To test the albedo's influence on $A_{s f c}$ and $A_{a t m}$ we computed all fluxes by assuming a constant $\alpha$ which we calculated from the MODIS data. The comparison of the shortwave energy balance fluxes as calculated using GLASS-AVHRR and constant albedo reveals that the albedo variability only has a minor influence on the $A_{s f c}$ and $A_{a t m}$ (not shown).

Finally, we calculate $A_{a t m}$ by subtracting $A_{s f_{c}}$ from $I_{t o a}^{\text {net }}$ from co-located DEEP-C data. These time series are then deseasonalized before we calculate annual mean anomalies for each station (if at least nine of twelve months are available per year). We only consider time series which have at least 15 annual mean values during the period 1985-2015. Finally, we average the annual anomaly time series of all stations in Europe and China.

\section{Sensitivity to station selection}

To estimate the uncertainties in the computation of the regional mean time series with respect to the station selection, we apply a bootstrapping approach $(\mathrm{N}=100)$ where we randomly select sub-samples of all available stations. For the sub-sample of stations we 
calculate the regional average time series as described above and compare it to the time series where all stations are used. We found that the resulting regional average time series and the corresponding trend estimates are rather insensitive to the station sampling. For example, when two thirds of all available stations are used for the bootstrapping, the mean standard deviation between the individual realizations for the regional mean is 0.2 / $0.4 / 0.5 \mathrm{~W} / \mathrm{m}^{2}$ for $I_{\text {toa }}^{\text {net }}, A_{\text {atm }}$ and $A_{s f c}$, respectively.

\section{Uncertainty estimation}

To propagate the measurement uncertainties to the regional average time series and to the trend estimated for the different periods we apply a bootstrapping approach $(\mathrm{N}=1000)$ where we artificially add Gaussian random noise to the measured time series. The standard deviation of the noise is chosen such that it corresponds to the $(1 \sigma)$ measurement uncertainties (including the spatial sampling error) of the different fluxes.

The station time series with the random noise are then processed as outlined above to calculate the regional means. For each realization we compute regional time series and the trend estimates for all periods. The differences in the trend estimates between the different realizations can be interpreted as propagated measurement uncertainties. We show the statistics of the different realizations of this bootstrapping approach in Figure 3 and in the corresponding tables in the supplemental material in terms of standard deviation of the slope estimate and percent of realizations which show statistical significant (Wald Test with t-distribution of the test statistic) trend estimates on the 95\%-level for a given period.

\section{Code availability}

All code used in this study to perform the analyses and to create the figures can be made available upon request from the corresponding author. 


\section{${ }_{373}$ Data availability}

374 The DEEP-C data is available via http://dx.doi.org/10.17864/1947.111. The GLASS

375 data is available via http://glcf.umd.edu/data/abd/. The BSRN data is available via

376 https://bsrn.awi.de/. The GEBA data is available via http://www.geba.ethz.ch/.

377 The CMA data can be accessed from the China Meteorological Administration http:

378 //www.cma.gov.cn/. 


\section{References}

[1] Wild, M. Global dimming and brightening: A review. Journal of Geophysical Research 114, D00D16 (2009).

[2] Ohmura, A. \& Lang, H. Secular variation of global radiation in Europe. In IRS '88: Current Problems in Atmospheric Radiation: International Radiation Symposium in Lille, France. 18-24. August 1988/Edited by Jacqueline Lenoble and JeanFrancois Geleyn, 98-301 (Deepak, Hampton, Virgina, USA, 1989).

[3] Wild, M. et al. From Dimming to Brightening: Decadal Changes in Solar Radiation at Earth's Surface. Science 308, 847-850 (2005).

[4] Yang, S., Wang, X. L. \& Wild, M. Homogenization and Trend Analysis of the 19582016 In Situ Surface Solar Radiation Records in China. Journal of Climate 31, 4529-4541 (2018).

[5] Abbot, C. G. \& Fowle, F. E. Radiation and terrestrial temperature. Annals of the Astrophysical Observatory of the Smithsonian Institution 2, 125-224 (1908).

[6] Wild, M. et al. The global energy balance from a surface perspective. Climate Dynamics 40, 3107-3134 (2013).

[7] Andreae, M. O., Jones, C. D. \& Cox, P. M. Strong present-day aerosol cooling implies a hot future. Nature 435, 1187-1190 (2005).

[8] Wild, M., Ohmura, A. \& Makowski, K. Impact of global dimming and brightening on global warming. Geophysical Research Letters 34, L04702 (2007).

[9] Wild, M. \& Liepert, B. The Earth radiation balance as driver of the global hydrological cycle. Environmental Research Letters 5, 025203 (2010).

[10] Ramanathan, V. et al. Atmospheric brown clouds: Impacts on South Asian climate and hydrological cycle. Proceedings of the National Academy of Sciences of the United States of America 102, 5326-5333 (2005). 
[11] Mercado, L. M. et al. Impact of changes in diffuse radiation on the global land carbon sink. Nature 458, 1014-1017 (2009).

[12] Ramanathan, V., Crutzen, P. J., Kiehl, J. T. \& Rosenfeld, D. Aerosols, Climate, and the Hydrological Cycle. Science 294, 2119-2124 (2001).

[13] Persad, G. G., Paynter, D. J., Ming, Y. \& Ramaswamy, V. Competing Atmospheric and Surface-Driven Impacts of Absorbing Aerosols on the East Asian Summertime Climate. Journal of Climate 30, 8929-8949 (2017).

[14] IPCC. Global Warming of 1.5 Degree C. An IPCC Special Report on the Impacts of Global Warming of 1.5 Degree C above Pre-Industrial Levels and Related Global Greenhouse Gas Emission Pathways, in the Context of Strengthening the Global Response to the Threat of Climate Change, Sustainable Development, and Efforts to Eradicate Poverty ([V. Masson-Delmotte, P. Zhai, H. O. Prtner, D. Roberts, J. Skea, P.R. Shukla, A. Pirani, W. Moufouma-Okia, C. Pan, R. Pidcock, S. Connors, J. B. R. Matthews, Y. Chen, X. Zhou, M. I. Gomis, E. Lonnoy, T. Maycock, M. Tignor, T. Waterfield (eds.)], 2018).

[15] Cess, R. D., Potter, G. L., Ghan, S. J. \& Gates, W. L. The climatic effects of large injections of atmospheric smoke and dust: A study of climate feedback mechanisms with one- and three-dimensional climate models. Journal of Geophysical Research: Atmospheres 90, 12937-12950 (1985).

[16] Menon, S., Hansen, J., Nazarenko, L. \& Luo, Y. Climate Effects of Black Carbon Aerosols in China and India. Science 297, 2250-2253 (2002).

[17] Shindell, D. \& Faluvegi, G. Climate response to regional radiative forcing during the twentieth century. Nature Geoscience 2, 294-300 (2009).

[18] Bond, T. C. et al. Bounding the role of black carbon in the climate system: A scientific assessment. Journal of Geophysical Research: Atmospheres 118, 5380$5552(2013)$. 
[19] Andrews, T., Forster, P. M., Boucher, O., Bellouin, N. \& Jones, A. Precipitation, radiative forcing and global temperature change. Geophysical Research Letters 37, L14701 (2010).

[20] Driemel, A. et al. Baseline Surface Radiation Network (BSRN): Structure and data description (19922017). Earth System Science Data 10, 1491-1501 (2018).

[21] Wild, M. et al. The Global Energy Balance Archive (GEBA) version 2017: A database for worldwide measured surface energy fluxes. Earth System Science Data 9, 601-613 (2017).

[22] Liang, S. et al. A long-term Global LAnd Surface Satellite (GLASS) data-set for environmental studies. International Journal of Digital Earth 6, 5-33 (2013).

[23] Allan, R. P. et al. Changes in global net radiative imbalance 19852012. Geophysical Research Letters 41, 5588-5597 (2014).

[24] Liu, C. et al. Evaluation of satellite and reanalysis-based global net surface energy flux and uncertainty estimates. Journal of Geophysical Research: Atmospheres 122, 6250-6272 (2017).

[25] Schwarz, M., Folini, D., Hakuba, M. Z. \& Wild, M. From Point to Area: Worldwide Assessment of the Representativeness of Monthly Surface Solar Radiation Records. Journal of Geophysical Research: Atmospheres 123, 13,857-13,874 (2018).

[26] Hakuba, M. Z., Sanchez-Lorenzo, A., Folini, D. \& Wild, M. Testing the homogeneity of short-term surface solar radiation series in Europe. In AIP Conference Proceedings, vol. 1531, 700-703 (AIP Publishing, 2013).

[27] Trenberth, K. E., Fasullo, J. T. \& Kiehl, J. Earth's Global Energy Budget. Bulletin of the American Meteorological Society 90, 311-324 (2009).

[28] Stephens, G. L. et al. An update on Earth's energy balance in light of the latest global observations. Nature Geoscience 5, 691-696 (2012). 
[29] Hakuba, M. Z., Folini, D. \& Wild, M. On the Zonal Near-Constancy of Fractional Solar Absorption in the Atmosphere. Journal of Climate 29, 3423-3440 (2016).

[30] Hakuba, M. Z., Folini, D., Schaepman-Strub, G. \& Wild, M. Solar absorption over Europe from collocated surface and satellite observations. Journal of Geophysical Research: Atmospheres 119, 3420-3437 (2014).

[31] Sanchez-Lorenzo, A. et al. Reassessment and update of long-term trends in downward surface shortwave radiation over Europe (1939-2012). Journal of Geophysical Research: Atmospheres 120, 9555-9569 (2015).

[32] Tang, W.-J., Yang, K., Qin, J., Cheng, C. C. K. \& He, J. Solar radiation trend across China in recent decades: A revisit with quality-controlled data. Atmospheric Chemistry and Physics 11, 393-406 (2011).

[33] Lu, Z. et al. Sulfur dioxide emissions in China and sulfur trends in East Asia since 2000. Atmospheric Chemistry and Physics 10, 6311-6331 (2010).

[34] Jin, Y., Andersson, H. \& Zhang, S. Air Pollution Control Policies in China: A Retrospective and Prospects. International Journal of Environmental Research and Public Health 13, 1219 (2016).

[35] Li, J., Jiang, Y., Xia, X. \& Hu, Y. Increase of surface solar irradiance across East China related to changes in aerosol properties during the past decade. Environmental Research Letters 13, 034006 (2018).

[36] Zheng, B. et al. Trends in China's anthropogenic emissions since 2010 as the consequence of clean air actions. Atmospheric Chemistry and Physics 18, 14095-14111 (2018).

[37] Folini, D., Dallafior, T. N., Hakuba, M. Z. \& Wild, M. Trends of surface solar radiation in unforced CMIP5 simulations. Journal of Geophysical Research: Atmospheres 122, 2016JD025869 (2017). 
[38] Wang, Y. W. \& Yang, Y. H. China's dimming and brightening: Evidence, causes and hydrological implications. Annales Geophysicae 32, 41-55 (2014).

[39] Kvalevg, M. M. \& Myhre, G. Human Impact on Direct and Diffuse Solar Radiation during the Industrial Era. Journal of Climate 20, 4874-4883 (2007).

[40] Xia, X. Spatiotemporal changes in sunshine duration and cloud amount as well as their relationship in China during 19542005. Journal of Geophysical Research: Atmospheres 115, D00K06 (2010).

[41] Li, M. et al. Anthropogenic emission inventories in China: A review. National Science Review 4, 834-866 (2017).

[42] Liu, Y., Wang, N., Wang, L., Guo, Z. \& Wu, X. Variation of cloud amount over China and the relationship with ENSO from 1951 to 2014. International Journal of Climatology 36, 2931-2941 (2016).

[43] Li, Z. et al. Aerosol and monsoon climate interactions over Asia. Reviews of Geophysics 54, 866-929 (2016).

[44] Wild, M. et al. The cloud-free global energy balance and inferred cloud radiative effects: An assessment based on direct observations and climate models. Climate Dynamics 52, 4787-4812 (2018).

[45] Gui, K. et al. Water vapor variation and the effect of aerosols in China. Atmospheric Environment 165, 322-335 (2017).

[46] Yang, S., Wang, X. L. \& Wild, M. Causes of Dimming and Brightening in China Inferred from Homogenized Daily Clear-Sky and All-Sky in situ Surface Solar Radiation Records (19582016). Journal of Climate 32, 5901-5913 (2019).

[47] Filonchyk, M. et al. Combined use of satellite and surface observations to study aerosol optical depth in different regions of China. Scientific Reports 9, 6174 (2019). 
[48] Sun, E. et al. Variation in MERRA-2 aerosol optical depth and absorption aerosol optical depth over China from 1980 to 2017. Journal of Atmospheric and SolarTerrestrial Physics 186, 8-19 (2019).

[49] Wang, R. et al. Estimation of global black carbon direct radiative forcing and its uncertainty constrained by observations. Journal of Geophysical Research: Atmospheres 121, 5948-5971 (2016).

[50] Ackerman, A. S. et al. Reduction of Tropical Cloudiness by Soot. Science 288, 1042-1047 (2000).

[51] Koch, D. \& Genio, A. D. D. Black carbon semi-direct effects on cloud cover: Review and synthesis. Atmospheric Chemistry and Physics 10, 7685-7696 (2010).

[52] Li, Z. et al. Aerosol optical properties and their radiative effects in northern China. Journal of Geophysical Research: Atmospheres 112, D22S01 (2007).

[53] Li, Z., Lee, K.-H., Wang, Y., Xin, J. \& Hao, W.-M. First observation-based estimates of cloud-free aerosol radiative forcing across China. Journal of Geophysical Research: Atmospheres (2010).

[54] Samset, B. H. et al. Climate Impacts From a Removal of Anthropogenic Aerosol Emissions. Geophysical Research Letters 45, 1020-1029 (2018).

[55] Boers, R., Brandsma, T. \& Siebesma, A. P. Impact of aerosols and clouds on decadal trends in all-sky solar radiation over the Netherlands (19662015). Atmos. Chem. Phys. 17, 8081-8100 (2017).

[56] Sanchez-Lorenzo, A. et al. Fewer clouds in the Mediterranean: Consistency of observations and climate simulations. Scientific Reports 7, 41475 (2017).

[57] Pfeifroth, U., Sanchez-Lorenzo, A., Manara, V., Trentmann, J. \& Hollmann, R. Trends and Variability of Surface Solar Radiation in Europe Based On Surfaceand Satellite-Based Data Records. Journal of Geophysical Research: Atmospheres 123, 1735- 1754 (2018). 
[58] Norris, J. R. \& Wild, M. Trends in aerosol radiative effects over Europe inferred from observed cloud cover, solar dimming, and solar brightening. Journal of Geophysical Research 112, D08214 (2007).

[59] Nabat, P., Somot, S., Mallet, M., Sanchez-Lorenzo, A. \& Wild, M. Contribution of anthropogenic sulfate aerosols to the changing Euro-Mediterranean climate since 1980. Geophysical Research Letters 41, 5605-5611 (2014).

[60] Granier, C. et al. Evolution of anthropogenic and biomass burning emissions of air pollutants at global and regional scales during the 19802010 period. Climatic Change 109, 163 (2011).

[61] Philipona, R., Behrens, K. \& Ruckstuhl, C. How declining aerosols and rising greenhouse gases forced rapid warming in Europe since the 1980s. Geophysical Research Letters 36, L02806 (2009).

[62] Ruckstuhl, C., Norris, J. R. \& Philipona, R. Is there evidence for an aerosol indirect effect during the recent aerosol optical depth decline in Europe? Journal of Geophysical Research: Atmospheres 115, D04204 (2010).

[63] Parding, K. M. et al. Influence of Synoptic Weather Patterns on Solar Irradiance Variability in Northern Europe. Journal of Climate 29, 4229-4250 (2016).

[64] Wild, M. How well do IPCCAR4/CMIP3 climate models simulate global dimming/brightening and twentiethcentury daytime and nighttime warming? Journal of Geophysical Research 114, D00D11 (2009).

[65] Allen, R. J., Norris, J. R. \& Wild, M. Evaluation of multidecadal variability in CMIP5 surface solar radiation and inferred underestimation of aerosol direct effects over Europe, China, Japan, and India. Journal of Geophysical Research: Atmospheres 118, 6311-6336 (2013).

[66] Roesch, A. et al. Assessment of BSRN radiation records for the computation of monthly means. Atmospheric Measurement Techniques 4, 339-354 (2011). 
[67] Schwarz, M., Folini, D., Hakuba, M. Z. \& Wild, M. Spatial Representativeness of Surface-Measured Variations of Downward Solar Radiation. Journal of Geophysical Research: Atmospheres 122, 13,319-13,337 (2017).

[68] Dutton, E. et al. Long-Term In-Situ Surface Flux Data Products. WCRP Report No. 19/2012: GEWEX Radiative Flux Assessment (RFA) Volume 1: Assessment, $135-158(2012)$

[69] Gilgen, H., Wild, M. \& Ohmura, A. Means and Trends of Shortwave Irradiance at the Surface Estimated from Global Energy Balance Archive Data. Journal of Climate 11, 2042-2061 (1998).

[70] Shi, G.-Y. et al. Data Quality Assessment and the Long-Term Trend of Ground Solar Radiation in China. Journal of Applied Meteorology and Climatology 47, 1006-1016 (2008).

[71] McArthur, L. J. B. Baseline Surface Radiation Network (BSRN). Operations Manual, Version 2.1. WMO/TD-No. 1274, World Climate Research Programme. World Meteorological Organization, Geneva, Switzerland, WCRP/WMO (2005).

[72] Wang, K., Ma, Q., Li, Z. \& Wang, J. Decadal variability of surface incident solar radiation over China: Observations, satellite retrievals, and reanalyses. Journal of Geophysical Research: Atmospheres 120, 6500-6514 (2015).

[73] Wielicki, B. A. et al. Clouds and the Earth's Radiant Energy System (CERES): An Earth Observing System Experiment. Bulletin of the American Meteorological Society 77, 853-868 (1996).

[74] Loeb, N. G. et al. Toward Optimal Closure of the Earth's Top-of-Atmosphere Radiation Budget. Journal of Climate 22, 748-766 (2009).

[75] Barkstrom, B. R. The Earth Radiation Budget Experiment (ERBE). Bulletin of the American Meteorological Society 65, 1170-1185 (1984). 
[76] Wong, T. et al. Reexamination of the Observed Decadal Variability of the Earth Radiation Budget Using Altitude-Corrected ERBE/ERBS Nonscanner WFOV Data. Journal of Climate 19, 4028-4040 (2006).

[77] Dee, D. P. et al. The ERA-Interim reanalysis: Configuration and performance of the data assimilation system. Quarterly Journal of the Royal Meteorological Society 137, 553-597 (2011).

[78] Mizielinski, M. S. et al. High-resolution global climate modelling: The UPSCALE project, a large-simulation campaign. Geoscientific Model Development 7, 16291640 (2014).

[79] Loeb, N. G. et al. Clouds and the Earths Radiant Energy System (CERES) Energy Balanced and Filled (EBAF) Top-of-Atmosphere (TOA) Edition-4.0 Data Product. Journal of Climate 31, 895-918 (2017).

[80] Shrestha, A. K. et al. Spectral unfiltering of ERBE WFOV nonscanner shortwave observations and revisiting its radiation dataset from 1985 to 1998. AIP Conference Proceedings 1810, 090008 (2017).

[81] Liu, Q. et al. Preliminary evaluation of the long-term GLASS albedo product. International Journal of Digital Earth 6, 69-95 (2013).

[82] Schaaf, C. B. \& Wang, Z. MCD43A1 MODIS/Terra+Aqua BRDF/Albedo Model Parameters Daily L3 Global - 500m V006 (2015).

[83] Schaaf, C. B., Liu, J., Gao, F. \& Strahler, A. H. Aqua and Terra MODIS Albedo and Reflectance Anisotropy Products. In Ramachandran, B., Justice, C. O. \& Abrams, M. J. (eds.) Land Remote Sensing and Global Environmental Change: NASA's Earth Observing System and the Science of ASTER and MODIS, Remote Sensing and Digital Image Processing, 549-561 (Springer New York, New York, NY, 2010). 


\section{Addendum}

Acknowleodgements This study was funded by the Swiss National Science Foundation grant 20002_159938/1 (Towards

607

608

Competingibnterests The authors declare that they have no competing financial interests.

Author contributions M.S., D.F., and M.W. designed the study. Y.S. processed the in-situ data over China. R.A. provided the DEEP-C data and helped interpreting it. M.S. did the coding and data analysis with help of all coauthors. M.S., D.F., M.W. wrote the paper with contributions from all coauthors.

Correspondence Correspondence and requests for materials should be addressed to Matthias Schwarz (email: matthias.schwarz.phd@gmail.com). 
a)

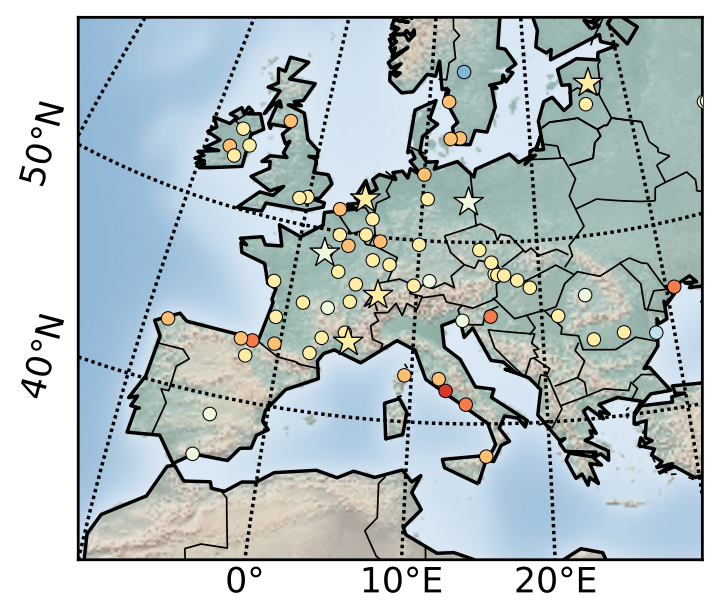

b)

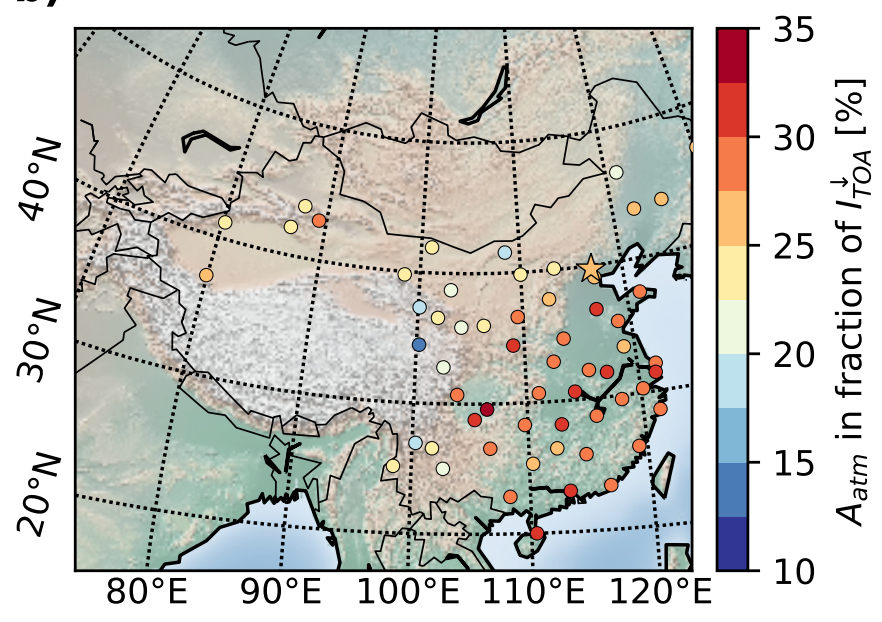

Figure 1: Long term mean (2000-2015) fractional atmospheric shortwave absorption $\left(A_{a t m}\right)$ for Europe (a) and China (b). Values are given as a fraction of TOA incoming radiation $\left(I_{\text {toa }}^{\downarrow}\right)$. Points show GEBA and CMA stations. Stars show BSRN stations. 


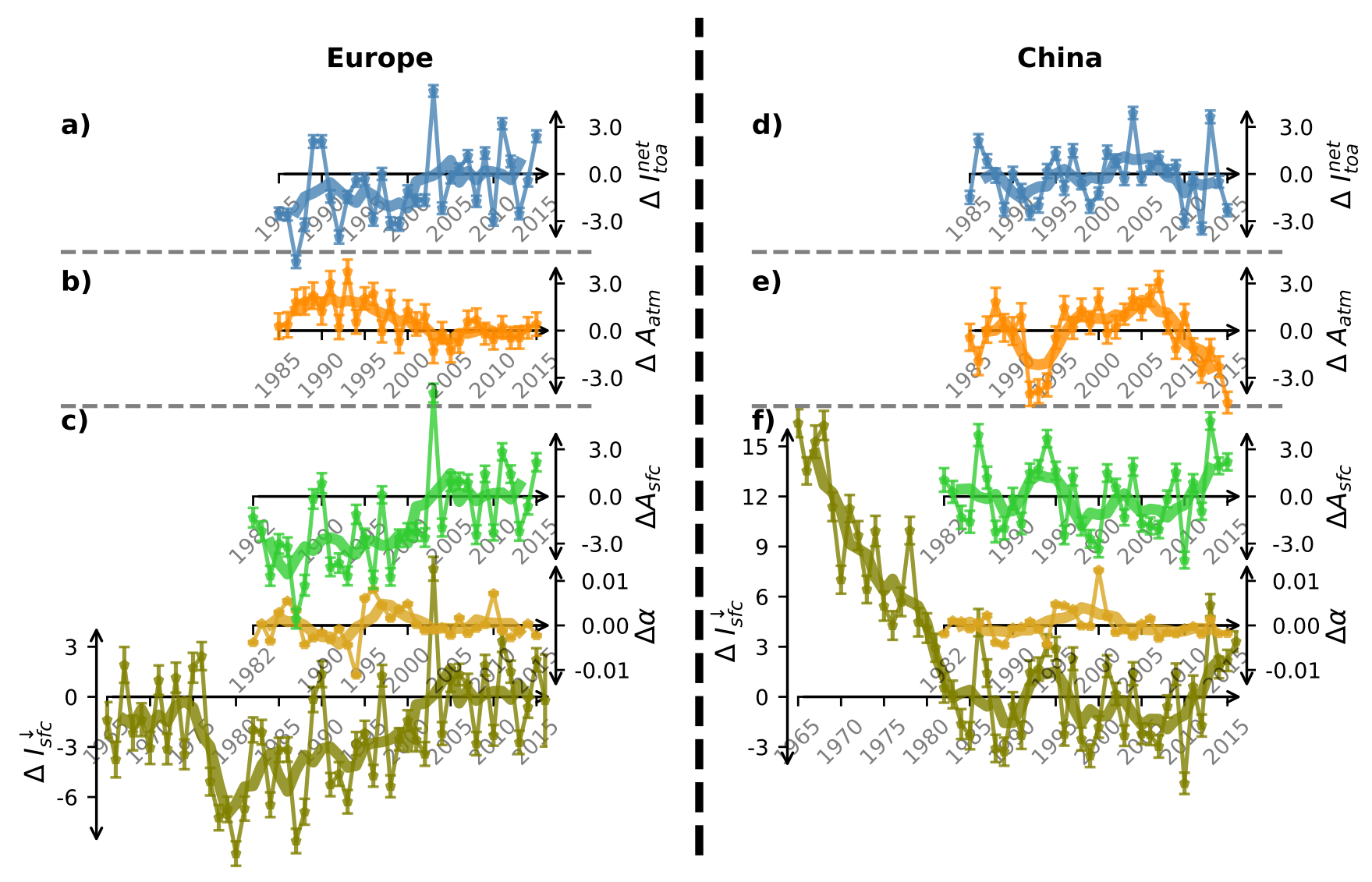

Figure 2: Anomaly time series of shortwave energy balance quantities. Shown are regional mean time series for Europe (a-c) and China (d-f) for TOA net shortwave flux (a,d), atmospheric shortwave absorption (b, e), as well as downward surface solar shortwave radiation, albedo, and surface shortwave absorption $(\mathrm{c}, \mathrm{f})$. Time series are shown as deviations $(\Delta)$ from long term means of the reference period 2000-2015 in $W / m^{2}$ for all fluxes and in albedo units for $\Delta \alpha$. Thin lines show station averaged annual means. Vertical bars indicate the $95 \%$ uncertainty range for propagated measurement uncertainties using a bootstrapping approach (as described in the methods section). Thick lines show centered five-year running means. 


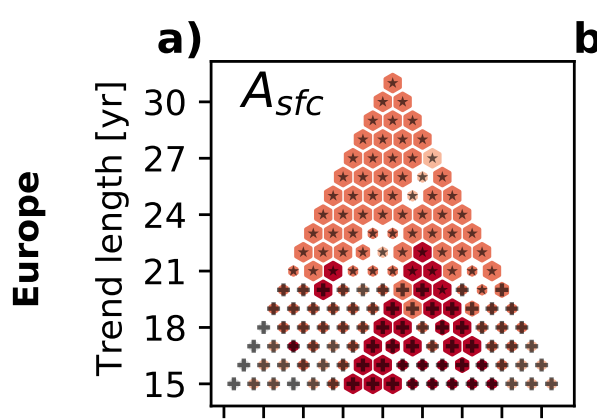

b)

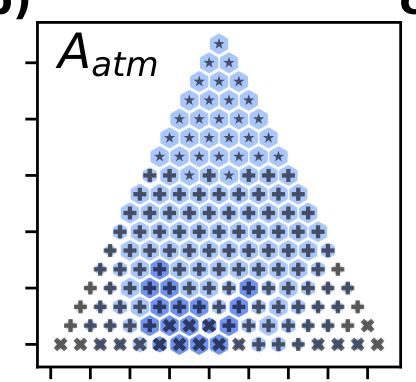

c)

d)

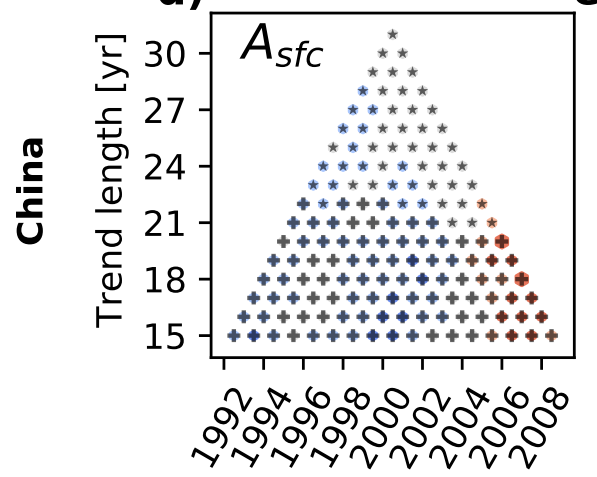

e)

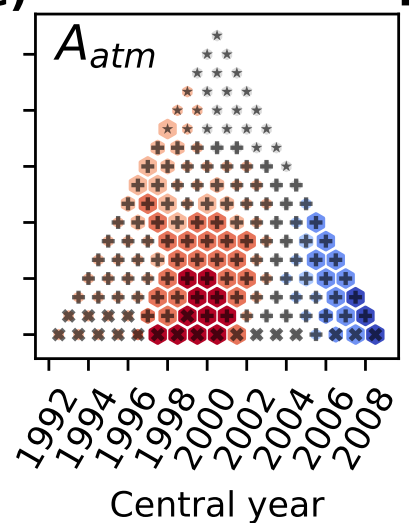

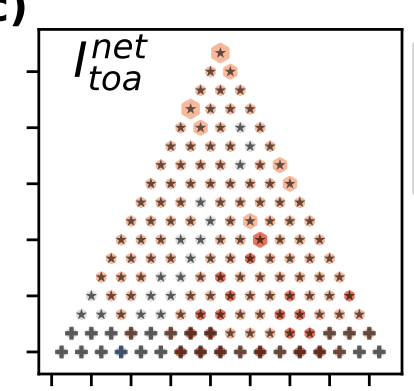

f)

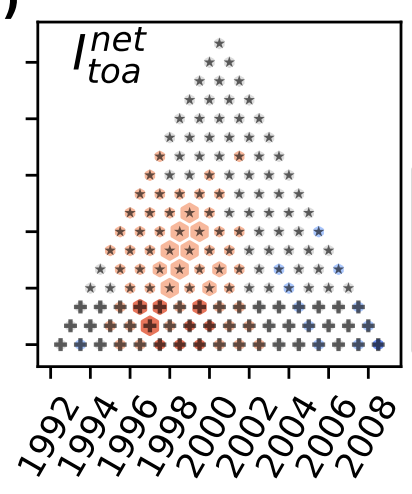

Significance

- low

- medium

- high

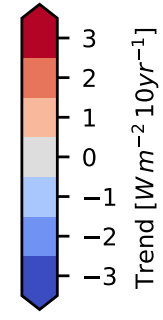

Slope uncertainty $\Delta s$ Values in $W / m^{2} /$ dec

* $\Delta s< \pm 0.2$

$+\quad \pm 0.2 \leq \Delta s< \pm 0.4$ * $\quad \pm 0.4 \leq \Delta s< \pm 0.5$

Figure 3: Trend matrices for surface shortwave absorption (a, d), atmospheric shortwave absorption (b, e), and TOA net shortwave radiation (c, f) for Europe (top row) and China (bottom row). Shown are linear trend estimates for different periods. The x-axis shows the central year of the trend window while the y-axis shows the length of the trend. The slopes, statistical significance, and uncertainties of the estimated trends are indicated by color, the size of the markers, and symbols, respectively. The uncertainties were derived by propagating the measurement uncertainties using a bootstrapping approach (see methods section for details). 

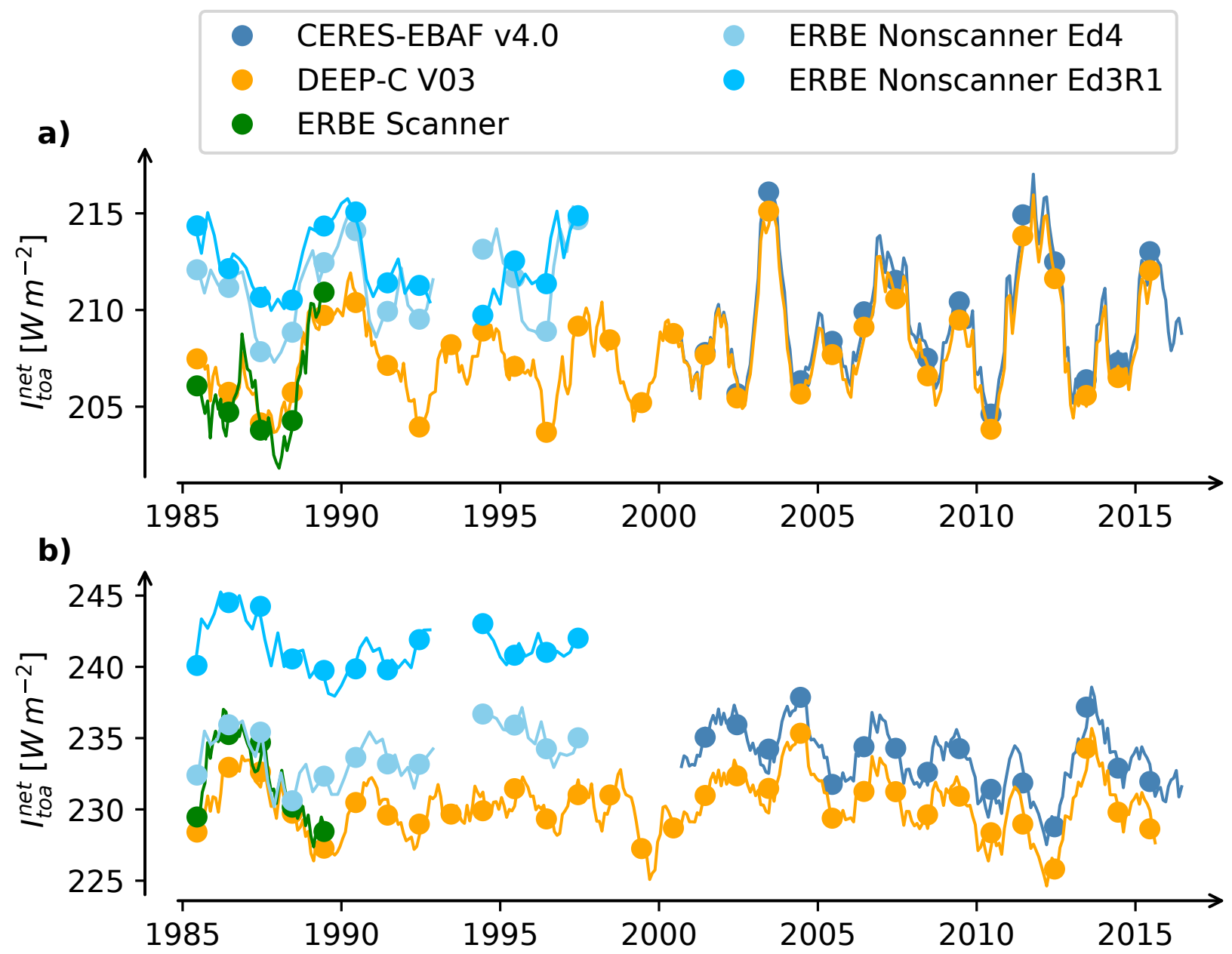

Figure 4: Comparison of TOA net shortwave fluxes from different data sources.

Shown are regional average TOA net shortwave flux time series of the CERES-

EBAF v.4.0, DEEP-C V03, ERBE Sanner, and ERBE Nonscanner (Ed3R1 and Ed4) data sets for (a) Europe $\left(40^{\circ} \mathrm{N}-50^{\circ} \mathrm{N} ; 10^{\circ} \mathrm{W}-20^{\circ} \mathrm{E}\right)$ and (b) China $\left(20^{\circ} \mathrm{N}-40^{\circ} \mathrm{N} ; 100^{\circ} \mathrm{E}-120^{\circ} \mathrm{E}\right)$. Points show annual means while the thin lines show 12-month running means. 